\title{
Teleconsultations in Oncology: The Way Forward?
}

\author{
Gaurav Aggarwal ${ }^{1 *}$, Sujoy Gupta ${ }^{2}$ and Priyanka Aggarwal ${ }^{3}$ \\ ${ }^{1}$ DNB Urology, Fellowship -Surgical Oncology, Consultant, Uro-Oncology, Tata Medical Center, West Bengal, India \\ ${ }^{2}$ FRCS Urology, Sr. Consultant, Uro-Oncology, Tata Medical Center, West Bengal, India \\ ${ }^{3}$ MD Dermatology, Consultant, Dermatology, Re-Incarnation: the Complete Skin Care Clinic, West Bengal, India \\ *Corresponding author: Gaurav Aggarwal, Consultant, Dept of Uro-Oncology, Tata Medical Center, Newtown, Kolkata, West Bengal, \\ India
}

\begin{tabular}{|c|c|}
\hline ARTICLE INFO & ABSTRACT \\
\hline Received: 慧 October 21, 2021 & $\begin{array}{l}\text { Citation: Gaurav Aggarwal, Sujoy Gupta, Priyanka Aggarwal. Teleconsultations in } \\
\text { Oncology: The Way Forward?. Biomed J Sci \& Tech Res 39(4)-2021. BJSTR. MS.ID.006347. }\end{array}$ \\
\hline
\end{tabular}

\section{Opinion}

Teleconsultation is defined as synchronous or asynchronous consultation using information and communication technology to omit geographical and functional distance [1]. The WHO defines telemedicine as: "Delivery of health-care services, where distance is a critical factor, by all health-care professionals using information and communications technologies for the exchange of valid information for diagnosis, treatment and prevention of disease and injuries, research and evaluation, and the continuing education of health-care workers, with the aim of advancing the health of individuals and communities" [2]. In the current COVID-19 pandemic, the use of telemedicine has increased by leaps and bounds- both by patients as well as health care providers. There are certain medical specialties where Teleconsults may be very useful, and maybe the way forward as well, viz. Dermatology, General Medicine, Diabetology, Endocrinology, Psychotherapy, to name a few. However, if we apply the same across all specialties- Oncology in general, and Surgical Oncology, in particular, seem to be the least efficacious towards "telemedicine". The Cancer sufferers are caught on the ledge of a precipice- Cancer on one end, and COVID at the other. But, is telemedicine the way out? The pros would be ability to allay anxiety, provide basic management and hope for a future "in person" consults. The cons include inability to manage any emergent situation or provide any definitive management to the patients. So- is there no role in Oncology? Effective teleoncology interventions may include cancer telegenetics, telepathology, bundling of cancer related teleapplications, remote chemotherapy supervision, symptom management, survivorship care, palliative care, and approaches to increase access to cancer clinical trials [3]. The Medical Council of India, in partnership with the NITI Aayog, has laid down certain guidelines for telemedicine, to provide Medical Practitioners to work within a specific framework. They have considered tele-consults to be equivalent to the "in -person" consults, both clinically, as well as economically. However, if we look at the satisfaction levels of patients, there seems to be a tremendous shortfall. The physician as well, faces several limitations, in accurately assessing the patients' clinical condition. Moreover, "in person" consults allow a more humane, personal and confidential approach, which go a huge way, not only in building the "patientdoctor" relationship, but also enabling a more wholesome approach to disease management. In a nutshell, Teleconsultations are here to stay, but their appropriate usage for optimal patient outcomes and satisfaction is still debatable.

\section{References}

1. Kolsoum Deldar, Kambiz Bahaadinbeigy, Seyed Mahmood Tara (2016) Teleconsultation and clinical decision making: a systematic review. Acta Inform Med 24(4): 286-292.

2. (1998) WHO. A health telematics policy in support of WHO's HealthFor-All strategy for global health development: report of the WHO group consultation on health telematics. Geneva.

3. Joseph Sirintrapun, Ana Maria Lopez (2018) Telemedicine in Cancer Care S. In: Joseph Sirintrapun, Ana Maria Lopez (Eds.)., Memorial Sloan Kettering Cancer Center, New York, USA. 
ISSN: 2574-1241

DOI: $10.26717 /$ BJSTR.2021.39.006347

Gaurav Aggarwal. Biomed J Sci \& Tech Res

(C) (P) This work is licensed under Creative

Submission Link: https://biomedres.us/submit-manuscript.php

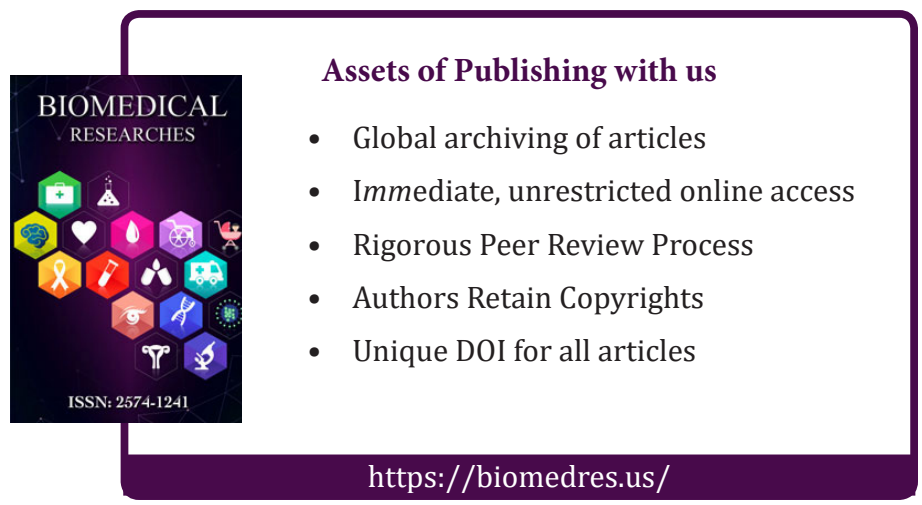

